\title{
ALTERAÇÕES ANATÔMICAS DURANTE O PERÍODO GESTACIONAL E SUAS REPERCUSSÕES PARA $O$ DESENVOLVIMENTO NEUROMOTOR DE CRIANÇAS COM SÍNDROME CONGÊNITA DO ZIKA VÍRUS
}

\author{
ANATOMIC CHANGES DURING THE GESTATIONAL PERIOD AND \\ THEIR REPERCUSSIONS FOR THE NEUROMOTOR DEVELOPMENT \\ OF CHILDREN WITH CONGENITAL ZIKA VIRUS SYNDROME
}

\author{
Luana da Silva Leal ${ }^{1}$ \\ Raquel Pontes de Brito $^{2}$ \\ Maryelli Laynara Barbosa de Aquino Santos ${ }^{3}$ \\ Luciana Karla Viana Barroso ${ }^{4}$
}

RESUMO: O Zika vírus constitui uma ameaça à saúde pública, pois a microcefalia resulta da infecção pelo mosquito Aedes aegypti infectado. No período gestacional, a mãe infectada pelo mosquito transmite o vírus para o bebê através da circulação materno-fetal e as crianças nascidas dessa gestação apresentam déficits globais e atraso no desenvolvimento neuromotor (DNPM), decorrentes de calcificações em determinadas áreas do cérebro. OBJETIVOS: Abordar as alterações anatômicas que interferem no DNPM dessas crianças; analisar os desafios e benefícios quanto à estimulação precoce. METODOLOGIA: Revisão de literatura, em que as buscas foram realizadas nas bases eletrônicas: SciELO, PubMed, LILACS, Google Acadêmico, Ministério da Saúde do Brasil, Instituto de Pesquisa com Células-tronco e Associação Brasileira de Fisioterapia Neurofuncional; entre os meses de Agosto a Novembro de 2019, nos idiomas Português e Inglês. RESULTADOS E DISCUSSÕES: O cérebro mesmo imaturo e em processo de desenvolvimento, ainda é capaz de perceber e receber sensações normais e de responder aos estímulos de forma adequada quando a criança é estimulada precocemente. CONCLUSÃO: Pesquisas recentes já apontam técnicas e métodos que podem beneficiar o

\footnotetext{
${ }^{1}$ Graduanda do curso de Fisioterapia do Centro Universitário - UNIFACISA, Campina Grande, Paraíba. E-mail: Luana.leal@maisunifacisa.com.br.

2 Graduanda do curso de Fisioterapia do Centro Universitário - UNIFACISA, Campina Grande, Paraíba.

${ }^{3}$ Graduanda do curso de Fisioterapia do Centro Universitário - UNIFACISA, Campina Grande, Paraíba.

${ }^{4}$ Docente de Saúde da Criança e Anatomia do Centro Universitário - UNIFACISA, Campina Grande,

Paraíba. E-mail: Ikarlab@yahoo.com.br.
} 
tratamento dessas crianças, no entanto, há uma carência de estudos que apontem o alcance desses recursos, bem como, em que momento do desenvolvimento serão melhores utilizados; portanto faz-se necessária a concepção de protocolos de tratamento que tragam resultados positivos, beneficiando esta população no futuro.

Palavras chave: Microcefalia; Zika vírus; Desenvolvimento Infantil.

ABSTRACT: The Zika virus is a threat to public health, as microcephaly results from infection by the infected Aedes aegypti mosquito. In the gestational period, the mother infected by the mosquito transmits the virus to the baby through the maternalfetal circulation and the children born from this pregnancy have global deficits and delayed neuromotor development (DNPM), resulting from calcifications in certain areas of the brain. OBJECTIVES: Address the anatomical changes that affect the DNPM of these children; analyze the challenges and benefits regarding early stimulation. METHODOLOGY: Literature review in which searches were conducted on electronic databases: SciELO, PubMed, LILACS, Google Scholar, Ministry of Health of Brazil, Stem Cell Research Institute and Brazilian Association of Neurofunctional Physiotherapy; between August and November 2019, in Portuguese and English. RESULTS AND DISCUSSION: The brain, even immature and in the process of development, is still able to perceive and receive normal sensations and to respond to stimuli properly when the child is stimulated early. CONCLUSIONS: Recent research already points out techniques and methods that can benefit the treatment of these children, however, there is a lack of studies that point out the reach of these resources, as well as, when they will be best used in development; therefore, it is necessary to design treatment protocols that bring positive results, benefiting this population in the future.

Keywords: Microcephaly; Zika virus; Child development. 


\section{INTRODUÇÃO}

O Zika vírus constitui atualmente uma ameaça relevante à saúde pública no Brasil e em todo o mundo. Este vírus foi isolado em um macaco sentinela rhesus, pela primeira vez, na floresta Zika em Uganda, em 1947. No Brasil, a notificação do vírus ocorreu em 2015 após um surto de dengue e um súbito aumento de casos de recém-nascidos com microcefalia, na região Nordeste do país (WHITE et al., 2016; SANTOS et al., 2019).

O Zika vírus pertence ao gênero Flavivirus da família Flaviviridae, junto a outros vírus como o da dengue, febre amarela e do Nilo Ocidental que partilham da mesma espécie. Cujo meio de transmissão, comum entre eles, ocorre por intermédio da picada do mosquito Aedes aegypti infectado. Em casos de gravidez, se a mãe foi alvo da picada de um mosquito infectado, poderá facilmente transmitir a infecção para a criança através da circulação materno-fetal, o que levará às repercussões a longo prazo como os defeitos congênitos, em especial a microcefalia, com consequente déficit neuromotor à criança (VALENTE; MORAES, 2019).

A microcefalia vem acompanhada de diversos distúrbios importantes ao crescimento da criança, acometendo especialmente o desenvolvimento motor, intelectual e cognitivo que variam de acordo com o grau de lesão do cérebro, e da extensão dessa lesão. Por esse motivo, a criança apresenta atraso global no desenvolvimento neuropsicomotor (DNPM) comprometendo a sequência fisiológica do DNPM, assim como déficits auditivos, físicos, intelectuais, cognitivos e ou visuais (NORBERT et al., 2016).

Sabendo que essas crianças já nascem em desvantagem em relação às demais, é de suma importância a inserção destas em um programa de estimulação precoce a fim de despertá-las a explorar suas competências e possibilidades, abordando os estopins que interferem em sua maturação, além de favorecer o seu desenvolvimento motor e cognitivo. Seu início deve ser imediato ao nascimento até os 3 anos de idade, pois é o momento propício à neuroplasticidade e, esse 
programa de estimulação é feito junto com uma equipe multidisciplinar em que o Fisioterapeuta também está inserido (NORBERT et al., 2016).

Particularmente, o Fisioterapeuta diante de seus conhecimentos e habilidades, terá papel importante na estimulação da sequência neuromotora do desenvolvimento da criança atuando junto à família, promovendo conhecimento para o autocuidado, possibilitando a extensão desse programa de estimulação no ambiente domiciliar durante as atividades do cotidiano (BRASIL, 2016).

Portanto, este estudo tem por objetivo abordar as principais alterações anatômicas que interferem no desenvolvimento neuromotor normal dessas crianças e analisar os desafios enfrentados quanto à estimulação precoce, bem como seus benefícios quando iniciado precocemente após o nascimento.

\section{METODOLOGIA}

O presente estudo trata-se de uma revisão de literatura em que foram utilizados artigos ou materiais que abordassem as alterações anatômicas, estimulação precoce, desenvolvimento neuropsicomotor e microcefalia; excluindo estudos com animais, bem como teses, monografias e dissertações. Os artigos foram selecionados das seguintes bases eletrônicas: SciELO, PubMed, LILACS, Google Acadêmico, Ministério da Saúde do Brasil, Instituto de Pesquisa com Células-tronco e Associação Brasileira de Fisioterapia Neurofuncional, durante os meses de Agosto Novembro de 2019, nos idiomas Português e Inglês; e as palavras-chave utilizadas foram: Microcefalia; Zika vírus; Desenvolvimento Infantil.

\section{RESULTADOS E DISCUSSÕES}


Inicialmente ao surto, o método mais utilizado para diagnóstico de microcefalia se dava por meio da medição do perímetro cefálico (PC). A medida é considerada leve quando o bebê apresenta O PC abaixo de dois desvios-padrão comparado à média de bebês com a mesma idade gestacional, e grave quando a criança apresenta perímetro cefálico abaixo de três desvios-padrão da média (NUNES et al., 2016).

No final de 2015, o Ministério da Saúde do Brasil revisou essa definição de diagnóstico e reduziu o critério do perímetro cefálico de $33 \mathrm{~cm}$ para $32 \mathrm{~cm}$, logo acredita-se que essas discussões acerca da circunferência do cérebro de prematuros, definem a forma de diagnóstico; e vale destacar a importância do uso da curva InterGrowth para uma melhor diferenciação do patológico para o normal (VICTORA et al., 2016).

Nunes et al (2016) em seu estudo ressaltou a importância de mensurar os dados do perímetro cefálico com as demais medidas do bebê não só para perceber sua relação de proporcionalidade, como também para evitar uma precipitação no diagnóstico. A medida do Perímetro Cefálico corresponde à circunferência frontooccipital e, é constantemente avaliada em consulta pediátrica, segundo Pires et al (2019), tendo o objetivo de monitorar possíveis desvios de desenvolvimento. É importante, pois reflete o crescimento cerebral e os dados obtidos devem ser registrados em gráficos próprios, de acordo com a idade e sexo da criança. No Brasil, as cadernetas de vacinação distribuídas pelo Ministério da Saúde contam com estes gráficos.

As alterações orais, craniofaciais, oculares, auditivas, de tônus muscular e a artrogripose são características ocasionadas pelo processo de instalação da doença, quando uma cepa do Zika vírus (MR766 de origem africana), infecta as células progenitoras neurais humanas (hNPCs) derivadas de células-tronco pluripotentes induzidas ocasionando essas deformações (CARVALHO et al., 2019). 
Figura 1 e 2. InterGrowth - Tabelas de referência para bebês do sexo feminino e masculino. $\mathrm{O}$ eixo $\mathrm{X}$ corresponde à idade gestacional ao nascimento e o $\mathrm{Y}$ a circunferência da cabeça.
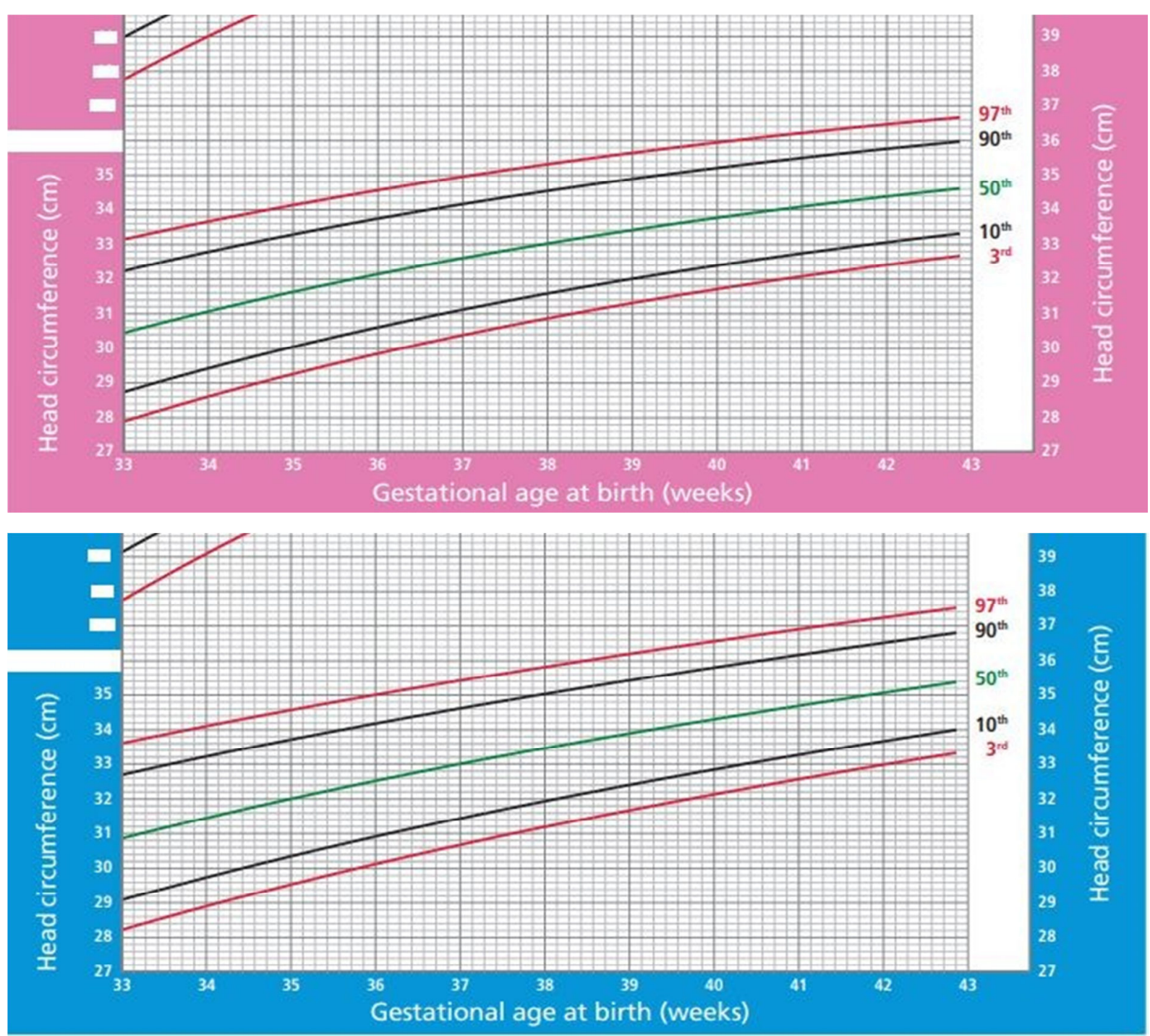

Fonte: MINISTÉRIO DA SAÚDE (2014).

As alterações orais, craniofaciais, oculares, auditivas, de tônus muscular e a artrogripose são características ocasionadas pelo processo de instalação da doença, quando uma cepa do Zika vírus (MR766 de origem africana), infecta as células progenitoras neurais humanas (hNPCs) derivadas de células-tronco pluripotentes induzidas ocasionando essas deformações (CARVALHO et al., 2019).

De acordo com o Instituto de Pesquisa com Células Tronco (IPCT, 2017) a microcefalia é o resultado do esgotamento das células-tronco que são responsáveis 
por fundar todas as células do cérebro maduro, dos neurônios e das células da glia. Logo, o Zika vírus atua impedindo a divisão celular neural do feto no início da gestação; desviando a proteína TBK1 que atua nesse processo de mitose, e mata essas células impedindo a formação de outras novas células resultando em microcefalia.

As infecções congênitas do sistema nervoso central estão ligadas à presença de calcificações intracranianas patológicas, cujas áreas comumente afetadas nesse processo são os núcleos da base, a substância branca e o córtex. Associado a essas estruturas, a criança pode apresentar distúrbios de movimento e crises epilépticas, assim como distúrbios na orientação, atenção, concentração, memória, inteligência e a capacidade de aprendizagem, coordenação visual-motora, dificuldade de deglutição, além de distúrbios do comportamento (TDAH e autismo). (CARDEAL, CARDEAL, 1999; ARAGÃO, 2015; SILVA, 2018).

Figura 3. Presença de calcificações em cérebro de bebê com microcefalia congênita por Zika vírus.

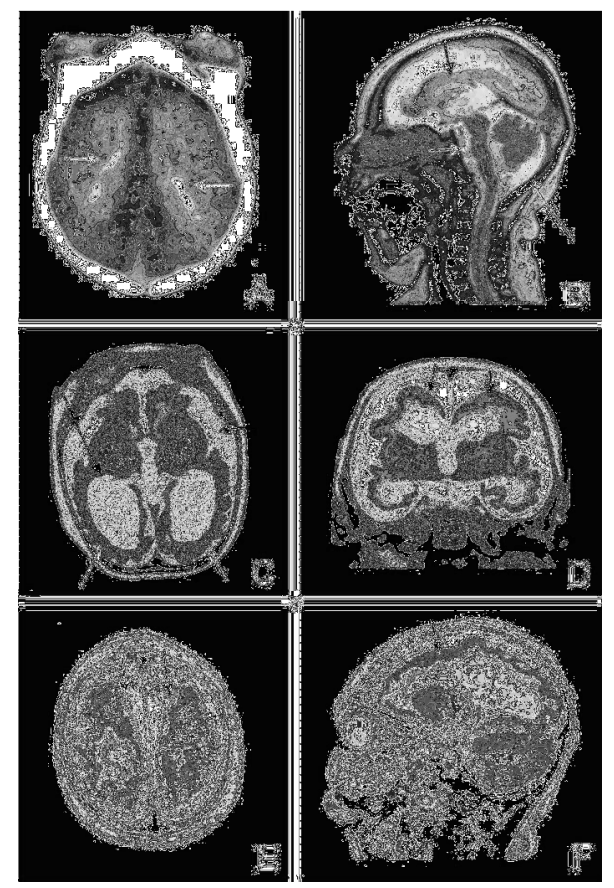

Fonte: ARAGÃO, 2015.

Aragão (2015) ressaltou os seguintes achados encontrados por outros e os elencou cada um deles da seguinte forma: 
1. Histopatologicamente: a presença de calcificações filamentosas granulométricas em forma de neurônio no córtex; astrogliose difusa com explosão astrocítica focal no espaço subaracnóideo; infiltrados perivasculares moderados, dispersos, com postos de células $T$ e B na matéria branca subcortical; reação intracitoplasmática granular em estruturas neuronais destruídas. $\mathrm{Na}$ placenta, presença de calcificações focais em vilosidades (MLAKAR et al., 2016).

2. Ultrassonografia: Presença de calcificações cerebrais generalizadas; disgênese do corpo caloso, vérmis e tálamo; cisterna magna dilatada; hemisférios cerebrais assimétricos; atrofia cerebral e deslocamento da linha mediana (SCHULER-FACCINI et al., 2016; ECDC,2015; MELO et al., 2016).

3. Déficit motor: Diminuição da amplitude de movimentos devido à presença do pé torto, o aumento de tônus muscular e a rigidez articular, o acometimento no quadril, alterações em joelhos, tornozelos e punhos, quadro de irritabilidade e convulsões.

Diante disso NORBERT et al (2016) enfatiza que a sequência fisiológica do desenvolvimento neuropsicomotor ou seja, o firmar a cabeça, sentar, engatinhar, andar, fazer transposições posturais, além de atividades como subir e descer escadas, pular, correr e as demais aquisições envolvidas serão amplamente comprometidas.

Por sua vez, SANTOS et al (2019) ressalta a importância da estimulação precoce nessas crianças, pontuando que o cérebro da criança, mesmo imaturo e em processo de desenvolvimento, ainda é capaz de perceber e receber sensações normais e de responder a elas dentro de suas limitações. BRASIL (2016) salienta que é por meio dela que acontece o desenvolvimento entre os vários sistemas orgânicos funcionais como: área motora, sensorial, perceptiva, proprioceptiva, linguística, cognitiva, emocional e social sendo elas dependente ou não da maturação do Sistema Nervoso Central (SNC).

Portanto, BRASIL (2016) apresenta várias técnicas que podem auxiliar o programa de estimulação precoce dentre elas, estão: o conceito neuroevolutivo Bobath, integração sensorial, estimulação sensorial de Rood e o Método Phelps. O método Bobath recebe destaque em virtude do seu conceito neuroevolutivo, pois usa o manuseio para proporcionar experiências sensoriais e motoras normais que darão 
base para o desenvolvimento motor, utilizando-se de abordagens sensório-motoras, estímulos sensoriais específicos são administrados para estimular uma resposta comportamental ou motora desejada.

É importante que a estimulação seja iniciada antes do terceiro trimestre de vida extra uterina, em virtude da neuroplasticidade que está em seu ápice, bem como as janelas da oportunidade; além das chances de bons resultados quanto aos ganhos nas habilidades sensório-motoras. Pouco se tem com relação a um protocolo ou tratamento padronizado que estimule o DNPM na microcefalia, contudo o que se tem indica que a Fisioterapia neurofuncional pediátrica é essencial na aquisição de habilidades motoras, interação com o ambiente, prevenção de deformidades e contraturas que podem agravar o quadro motor e até o respiratório (ABRAFIN, 2016).

Sabe-se que muitos são os desafios enfrentados pelas famílias, e estes se tornam fatores que podem influenciar na procura tardia por ajuda: a falta de informação, o grau de instrução, o estado civil dessas mães que muitas vezes são abandonadas pela condição do bebê e passam a assumir o papel de prover o sustento da família, sendo obrigadas a deixar a criança com terceiros que por sua vez negligenciam o tratamento desta; a falta de recursos ou seja, o nível sócio econômico, o deslocamento difícil principalmente de mães que moram na zona rural, além de fatores emocionais como o medo e a negação frente ao diagnóstico. Todos estes fatores podem interferir na inserção desta criança em um programa de estimulação (CAMPOS et al., 2018).

Com relação a este último fator, uma pesquisa mostrou que os pais e mães podem passar por um momento de negação inicial, seguida da fase de desestruturação e por último a de adaptação, em que os pais acabam se conformando com o diagnóstico da criança e percebenm as necessidades que esta possui, estabelecendo, assim, relação de afeto e paciência (CAMPOS et al., 2018).

\section{CONSIDERAÇÕES FINAIS}


Desde o surto de casos de microcefalia no Brasil no ano de 2015, a comunidade científica tem se empenhado em entender como acontece o processo de instalação dessa infecção, como o cérebro da criança é afetado e as repercussões deste evento. Sabe-se que algumas técnicas tem sido benéficas para este público e inclusive algumas foram citadas no presente estudo, porém há uma carência de literaturas que apontem qual técnica traz melhores resultados, ou em qual momento elas serão melhor utilizadas. É de grande relevância que protocolos de estimulação sejam desenvolvidos, enfatizando o desenvolvimento neuromotor a fim de minimizar os danos promovidos pelo Zika vírus.

\section{REFERÊNCIAS BIBLIOGRÁFICAS}

ARAGAO, Maria de Fatima Vasco et al. Clinical features and neuroimaging (CT and MRI) findings in presumed Zika virus related congenital infection and microcephaly: retrospective case series study. Bmj, v. 353, p. i1901, 2016.

BRASIL. ASSOCIAÇÃO BRASILEIRA DE FISIOTERAPIA NEUROFUNCIONAL PARECER SOBRE ESTIMULAÇÃO PRECOCE E MICROCEFALIA. Rio de Janeiro. 29 jan. 2016. Disponivel em:

<http://abrafin.org.br/wp-content/uploads/2015/02/PARECER-MICROCEFALIA.pdf>. Acesso em: 13 out. 2019.

BRASIL. Diretrizes de estimulação precoce: crianças de zero a 3 anos com atraso no desenvolvimento neuropsicomotor decorrente de microcefalia. Ministério da Saúde, Brasil, $2016 . \quad$ Disponível em: $<$ http://portalarquivos2.saude.gov.br/images/pdf/2016/janeiro/13/Diretrizes-de-Estimulacao-P recoce.pdf>. Acesso em: 28 jan. 2020.

CAMPOS, Mara Marusia Martins Sampaio et al. Challenges and perspectives of mothers of children with microcephaly due to Zika virus infection. Revista da Rede de Enfermagem do Nordeste, Ceará, 21 nov. 2018.

CARDEAL, José Osmar; CARDEAL, Daniel Dante. "Calcificação simétrica dos gânglios da base (CSGB)," Doença de Fahr. Rev Neurociências, v. 7, n. 1, p. 28-31, 1999.

CARVALHO, Isabella Fernandes et al. Clinical and $\mathrm{x}$-ray oral evaluation in patients with congenital Zika Virus. Journal Of Applied Oral Science, [s.I.], v. 27, 20 maio 2019.

ECDC - EUROPEAN CENTRE FOR DISEASE PREVENTION AND CONTROL. Zika virus epidemic in the Americas: potential association with microcephaly and Guillain-Barré syndrome. 2015.

FEITOSA, lan Mikardo Lima; SCHULER-FACCINI, Lavinia; SANSEVERINO, Maria Teresa Vieira. Aspectos importantes da Síndrome da Zika Congênita para o pediatra e o neonatologista. Boletim Científico de Pediatria,v. 5, n. 3, p.75-80, 2016.

IPCT. Células-tronco neurais revelam como o Zika vírus pode causar microcefalia e um 
potencial tratamento farmacológico. Instituto de Pesquisa Com Células-tronco, [S.I.], 11 ago. 2017. Disponível em: <http://celulastroncors.org.br/celulas-tronco-neurais-revelam-como-o-zikavirus-pode-causar- microcefalia-e-um-potencial-tratamento-farmacologico/>. Acesso em: 05 set. 2019.

MELO, A. S. Oliveira et al. Zika virus intrauterine infection causes fetal brain abnormality and microcephaly: tip of the iceberg?. Ultrasound In Obstetrics \& Gynecology, v. 47, n. 1, p.6-7, jan. 2016.

MLAKAR, Jernej et al. Zika Virus Associated with Microcephaly. New England Journal of Medicine, v. 374, n. 10, p.951-958, 2016.

NORBERT, Adriana Andreia De Fatima et al. A importância da estimulação precoce na microcefalia. Universidade Regional do Noroeste do Estado do Rio Grande do Sul. Salão do Conhecimento, [S.I.], set. 2016.

NUNES, Magda Lahorgue et al. Microcephaly and Zika virus: a clinical and epidemiological analysis of the current outbreak in Brazil. Jornal de Pediatria, Rio de Janeiro, v. 92, n. 3, p.230240, maio 2016.

PIRES, Livia et al. Microcephaly: investigation and diagnostic approach. Residência Pediátrica, Rio de Janeiro, v. 9, n. 1, p.70-79, 2019.

SANTOS, Daniel Batista Conceição dos et al. Sensibilização das mães de crianças com microcefalia na promoção da saúde de seus filhos. Revista da Escola de Enfermagem da Usp, São Paulo, v. 53, 2019.

SILVA, Alexandre Ferreira da. Differential diagnosis of pathological intracranial calcifications in patients with microcephaly related to congenital Zika virus infection. Radiologia Brasileira, São Paulo, v. 51, n. 4, p.270-271, ago. 2018.

VALENTE, Ana Paula; MORAES, Adolfo Henrique. Zika virus proteins at an atomic scale: how does structural biology help us to understand and develop vaccines and drugs against Zika virus infection? Journal Of Venomous Animals And Toxins Including Tropical Diseases, São Paulo, v. 25, 2019.

VICTORA, Cesar Gomes et al. Microcephaly in Brazil: how to interpret reported numbers?. The Lancet, [s.I.], v. 387, n. 10019, p.621-624, fev. 2016.

WHITE, Martyn K. et al. Zika virus: An emergent neuropathological agent. Annals Of Neurology, [s.I.], v. 80, n. 4, p.479-489, 10 ago. 2016. 